\title{
Construcciones de juventud y trayectorias militantes católicas contemporáneas en parroquias del Gran Buenos Aires
}

\author{
Natalia Soledad Fernández \\ Conicet, Argentina*
}

fernandez.nt@gmail.com

\section{Resumen (analítico)}

El artículo analiza las construcciones de juventud presentes en la Acción Católica Argentina y sus vínculos con trayectorias de jóvenes militantes insertos en parroquias del Gran Buenos Aires. Para el abordaje metodológico cualitativo se utilizan los siguientes materiales de campo, producidos entre 2016 y 2018: entrevistas en profundidad realizadas a jóvenes católicos, registros de observación participante en parroquias y eventos nacionales de Acción Católica Argentina y análisis de documentos institucionales. Dentro de la Acción Católica Argentina, se identifican tensiones entre las definiciones de juventud producidas por la institución y las trayectorias juveniles. Los jóvenes experimentan modos de «ser» y de «vivir» la juventud distintos a los propuestos por la Acción Católica Argentina, acordes con los cambios sociales y culturales que se produjeron en Argentina en las últimas décadas.

\section{Palabras clave}

Juventud, catolicismo, instituciones, trayectorias, sentidos, Argentina.

\section{Tesauro}

Tesauro de Ciencias Sociales de la Unesco.

\section{Para citar este artículo}

Fernández, N. S. (2020). Construcciones de juventud y trayectorias militantes católicas contemporáneas en parroquias del Gran Buenos Aires. Revista Latinoamericana de Ciencias Sociales, Niñez y Juventud, 18(2), 1-30. http://dx.doi.org/ 10.11600/1692715x.18209

\section{Historial}

Recibido: 23.07.2019

Aceptado: 17.01.2020

Publicado: 25.05.2020

\section{Información artículo}

Este artículo se basa en la investigación sociológica «Juventudes, militancias y voluntariados en el catolicismo argentino: un estudio comparado entre la Acción Católica Argentina y Scouts de Argentina Asociación Civil (Área Metropolitana de Buenos Aires, 1983-2020)» finalizada en 2020. Contó con el apoyo del Consejo Nacional de Investigaciones Científicas y Técnicas (Conicet), resolución D N 3902. Gran área: Ciencias Sociales. Área: Sociología. 


\section{Constructions of youth and contemporary militant trajectories in parishes in Gran Buenos Aires (Argentina)}

\section{Abstract (analytical)}

This article analyzes the constructions of youth produced in the Acción Católica Argentina (Argentinian Catholic Action) organization and their link with the trajectories of militant youth living in parishes of Gran Buenos Aires. Field materials produced between 2016 and 2018 are analyzed using a qualitative methodological approach that consists of: in-depth interviews with Catholic youth; participant observation records from parish and national Argentinian Catholic Action events; and the analysis of institutional documents. In Argentinian Catholic Action, tensions were identified between the definitions of youth produced by the institution and young people's own trajectories. Young people experience ways of «being» and «living» that are different from those proposed by the Argentinian Catholic Action and that respond to the social and cultural changes produced in Argentine society in recent decades.

Keywords

Youth, catholicism, institutions, trajectories, meaning, Argentina.

\section{Construções juvenis e trajetórias militantes contemporâneas nas paróquias da grande Buenos Aires (Argentina)}

\section{Resumo (analítico)}

O artigo analisa as construções de jovens presentes na Acción Católica Argentina seus vínculos com as trajetórias de jovens militantes inseridos nas paróquias da Gran Buenos Aires. Para a abordagem metodológica qualitativo, são utilizados materiais de campo produzidos entre 2016 e 2018, que consistem em entrevistas em profundidade com jovens católicos; registros de observação participante nas paróquias e eventos nacionais da Acción Católica Argentina e análise de documentos institucionais. Na Acción Católica Argentina, são identificadas tensões entre as definições de juventude produzidas pela instituição e as trajetórias da juventude. Os jovens experimentam maneiras de «ser»e «viver» a juventude diferentes dos propostos pela Acción Católica Argentina de acordo com as mudanças sociais e culturais produzidas na Argentina nas últimas décadas.

\section{Palavras-chave}

Juventude, catolicismo, instituições, trajetórias, sentidos, Argentina.

Información autora

[*] Doctoranda en Sociología del Instituto de Altos Estudios Sociales. Universidad Nacional General San Martín. Licenciada y profesora en Ciencias Sociales, Universidad Nacional de Quilmes. Becaria doctoral Conicet. Correo electrónico: fernandez.nt@gmail.com (iD) 0000-0001-7841-9889. 


\section{Introducción}

esde principios del siglo XX el papel otorgado a los jóvenes a nivel mundial y
local ha sido central en diversas instituciones, movimientos y agrupaciones. ${ }^{1}$ Hasta ese momento, en las sociedades occidentales «había jóvenes pero no juventud» (Torre, 2010), es decir, la juventud no era una etapa vital diferenciada de la niñez y de la adultez. Las instituciones creadas por adultos se orientaban a controlar, moldear y perfilar prácticas, valores y creencias de los sujetos juveniles en pos de distintos proyectos sociales, políticos y religiosos.

En Argentina se destaca el rol de la Iglesia católica y de sus «especialistas religiosos»² (Cattogio, 2010a) en la fundación de distintas instituciones que, a lo largo de los años, crearán al militante católico, un nuevo actor social capaz de desarrollar el proyecto del «catolicismo integral» (Mallimaci, 1991, 1992). Este fenómeno constituyó una forma de catolicismo en respuesta al avance secularizador del liberalismo y del socialismo que intentaban limitarlo a un ámbito privado. Así, buscó integrar todas las esferas de la vida social (política, religiosa, pública y privada) para avanzar sobre la sociedad y el Estado. Para ello se valió de distintas instituciones como la Acción Católica Argentina (en adelante ACA) creada en 1931 (Mallimaci, 1991).

El estudio de la ACA es de especial interés en tanto permite observar dos procesos sociales relevantes vinculados a la conformación de militantes y militancias católicas. Por un lado, la emergencia, desarrollo y transformación de un tipo de joven vinculado con las jerarquías católicas a lo largo de los siglos XX y XXI. Por otro, la difusión de movimientos especializados de importante participación juvenil y la futura inserción de sus miembros en diferentes instituciones sociales y políticas más amplias entre los años 1969

${ }^{1}$ Véase Mallimaci (1991) y Mardomingo y Díaz (2003).

${ }^{2}$ El concepto especialistas religiosos refiere a la posición privilegiada que la jerarquía eclesial (obispos, sacerdotes, religiosas) ocupa en el espacio social, como parte de una institución que cuenta con una larga tradición y está dotada de legitimidad para amplios sectores de la sociedad argentina. 
y 1979 en Argentina (Dominella, 2012; Donatello, 2010). Este último aspecto se articula con los cambios sociales y culturales acaecidos a partir de los años cincuenta, donde la juventud comenzó a configurarse como categoría y etapa vital destacada a nivel local e internacional (Manzano, 2010). Así mismo, la ACA constituye un espacio de formación de «cuadros católicos» a partir de la configuración de sociabilidades, redes sociales y militancias en parroquias (Bidegain, 2009; Bottinelli et al., 2001; Blanco, 2011; Cattogio, 2010b; Dominella, 2015; Soneira, 2008).

Este artículo parte de un interés general por comprender y analizar la conformación de instituciones católicas destinadas a los y las jóvenes que fueron creadas a principios del siglo XX y que se encuentran actualmente en vigencia. En particular, se abordarán las construcciones de juventud delineadas por la ACA y los modos en que dichas construcciones se vinculan con las trayectorias de jóvenes militantes insertos en parroquias del Gran Buenos Aires entre los años 2016 y 2018.

La amplia trayectoria de la ACA en la escena pública local e internacional a lo largo del siglo XX ha sido extensamente tratada — desde un enfoque sociohistórico- por diversos autores. Mallimaci (1991, 1992, 1996, 2000, 2015) aborda el surgimiento y desarrollo de la ACA y el rol que desempeñaron las ramas juveniles en la llamada «cruzada de la Iglesia Católica» por «ganar la calle» (resistiéndose a que la religión quedara circunscripta a una esfera privada) y por «ganar a las juventudes» (contra comunistas, socialistas y liberales). Paralelamente, el estudio de la ACA le permite comprender la sociedad argentina luego de la primera guerra mundial. De acuerdo con Lida (2009) y Lida y Mauro (2009), la difusión del catolicismo integral supuso la previa constitución de una sociedad de masas que acompañó dicho catolicismo. Los autores proponen, por tanto, observar otros procesos previos a 1930, como la modernización argentina, la industrialización, la intervención política de amplios sectores, el papel público de la mujer y la ocupación de las calles.

Romero (1998, 2010) estudia la parroquialización y las movilizaciones católicas en Buenos Aires entre 1934 y 1946, que permitieron que la Iglesia católica asumiera una posición militante y recristianizadora de la sociedad, diferente a la de otros espacios de sociabilidad como los clubes de barrio y las sociedades de fomento. El autor permite visibilizar un campo de disputa entre distintos actores por la ocupación del espacio social y del tiempo libre de los sujetos. En este proceso, el «mito de la nación católica» (Zanatta, 1996) fue central para movilizar diversos actores del catolicismo y configurar a la Iglesia católica como actor sociopolítico (Bianchi, 2002). 
Por su parte, Caimari (1994) reconstruye los vínculos entre el catolicismo y el peronismo entre 1943 y 1955 en Argentina y destaca el rol que desempeñaron los movimientos juveniles de la ACA en la formación de cuadros católicos desde 1930. Bidegain (2009) indaga los modelos femeninos y masculinos tradicionales construidos por la Juventud Universitaria Católica entre los años 1950 y 1964. La autora plantea que la participación femenina en la Juventud Universitaria Católica preparó a las mujeres para desarrollar actividades de responsabilidad en la vida política, social y académica.

Cattogio (2010b) profundiza en las trayectorias de religiosas y rastrea su participación durante la infancia y juventud como dirigentes de la ACA y como militantes de espacios políticos universitarios. Mientras que Dominella (2012, 2015, 2018, 2019) estudia el proceso de activación juvenil en los años sesenta y setenta en la Juventud Universitaria Católica, la Juventud Obrera Católica y la Juventud Estudiantil Católica de Bahía Blanca (Argentina). La autora reconstruye, entre otros: las tensiones entre religión y política; los espacios de sociabilidad y las redes del catolicismo liberacionista; el método de «revisión de vida» y su vínculo con trayectorias militantes. A su vez, Blanco (2008, 2011) analiza los sentidos del ser joven en la Iglesia argentina a mediados del siglo XX a partir del análisis de documentos de la Juventud de Acción Católica y la Juventud Obrera Católica.

Por su parte, Cammarota $(2015,2017)$ estudia el asociacionismo en la Juventud de la Acción Católica, la formación de los jóvenes mediante el apostolado celular, la inserción barrial, las relaciones políticas del contexto que «competían» con la Juventud de Acción Católica y la construcción del perfil del joven militante entre 1940 y 1950.

Desde un enfoque antropológico, Fora (2002) analiza los procesos de construcción de identidades católicas juveniles en grupos parroquiales de la ciudad de La Plata, haciendo foco en las trayectorias de jóvenes católicos. Los vínculos entre religión y construcciones de juventud han sido abordados por Mosqueira (2014) en el evangelismo-pentecostal.

Si bien, estos estudios son centrales para comprender la conformación y las derivas de la ACA en el contexto local, es de especial interés conocer las formas en que sus miembros se relacionan con la institución en la actualidad, desde un enfoque sociológico y situado en sus propios escenarios de acción.

Los propósitos de este artículo aluden a la necesidad de comprender y analizar los modos de ser joven y de vivir la juventud por parte de jóvenes católicos insertos en parroquias, al tratarse de experiencias poco conocidas por la sociología de las juventudes y por la sociología de las religiones. De acuerdo con Chaves (2009), la mayoría de las investiga- 
ciones sobre jóvenes y religiones han estudiado a grupos que comparten una misma fe, sin discriminar las prácticas específicas de las juventudes que han sido observadas como parte de un grupo mayor. Justamente, este artículo se realiza para profundizar y visibilizar a las juventudes como actores centrales de una de las instituciones católicas de mayor trayectoria en Argentina. Así mismo, se identifica a las parroquias como escenarios sociales de vital importancia para la configuración de identidades católicas juveniles diversas.

$\mathrm{Al}$ respecto, en los distintos apartados nos preguntamos: ¿qué concepciones sobre lo juvenil se producen en la ACA?, ¿cómo perciben las juventudes católicas los modelos de juventud propuestos institucionalmente?, ¿qué trayectorias trazan las juventudes?, ¿cómo se vinculan dichas trayectorias con los modelos propuestos por la ACA?, y ¿de qué manera los cambios sociopolíticos de los últimos años —vinculados a los debates sobre la interrupción voluntaria del embarazo, la diversidad de género, el matrimonio igualitario, entre otros-y los tránsitos de los y las jóvenes por otros espacios no religiosos intervienen en las trayectorias juveniles católicas?

La perspectiva teórica de este trabajo concibe a las clasificaciones etarias como invenciones históricas arbitrarias que estructuran la percepción, las conductas y los valores que los actores y actrices tienen del mundo social que les rodea (Bourdieu, 1992; Chaves, 2009; Margulis \& Urresti, 1998).

De acuerdo con Manzano (2010, 2018), antes que un estadio biológico, la juventud es una categoría cargada de sentido sociocultural, constituida en relación a distintos procesos sociales luego de la segunda posguerra. En Argentina, la ampliación de la matriculación escolar y universitaria, la extensión de espacios de ocio y consumo, así como la «juvenilización» de la cultura de masas se imbricaron con la redefinición de las relaciones de género y la moral sexual. En los años sesenta, la autoridad y la tradición comenzaron a desgastarse a medida que comenzó a cobrar relevancia la promesa de cambio asociada a la juventud. De acuerdo con Manzano (2010) «fue en relación con los consumos que la juventud se visibilizó como un actor con fuerza propia» (p. 26). Finalmente, con las revueltas populares de 1969 , que tuvieron a los estudiantes universitarios y secundarios como protagonistas, las juventudes y la categoría de juventud comenzarob a politizarse.

Siguiendo a Reguillo (2000), la categoría juventud supone un análisis de las diversas prácticas, comportamientos y universos simbólicos que esta puede incluir, articulada además con variables como clase, género, cultura, contexto socioeconómico, entre otras. Por tanto, la juventud es una «categoría analítica que cobra sentidos al insertarse en el mundo social» (Chaves, 2009, p. 15). Por ello, nos referimos a «juventudes» (y no a «ju- 
ventud») considerando diversas posibilidades de constitución, aparición y presentación del sujeto juvenil en la sociedad argentina (Braslavsky, 1986; Martín-Criado, 1998; Larrondo \& Vommaro, 2013) y, en consecuencia, diversas formas de habitar la categoría de juventud por parte de los y las jóvenes de acuerdo a su clase, género, cultura y creencias.

Las trayectorias remiten a las experiencias de vida, prácticas y estrategias trazadas por actores y actrices sociales dentro de la ACA. De acuerdo con Dubet (2010), las experiencias constituyen actividades cognitivas, maneras de construir lo real y de verificarlo. Entre las trayectorias de la ACA, se consideran las experiencias, concepciones y prácticas juveniles en torno a la conformación de noviazgos, profesiones, trabajos, participación parroquial y, en estos recorridos, los distintos modos de construir juventud en articulación con los modelos propuestos por la ACA.

\section{Metodología}

El trabajo se basa en dos tradiciones de investigación cualitativa: la etnografía y las historias de vida. Un diseño de investigación cualitativa permite articular los elementos constitutivos del mismo y realizar modificaciones de manera paulatina a lo largo del proceso de investigación, enriqueciendo el análisis final (Vasilachis, 2006).

Las técnicas para construir la información han sido entrevistas en profundidad, observación participante (Guber, 2001) en parroquias y reuniones nacionales y análisis de publicaciones institucionales. Las entrevistas en profundidad indagaron en las historias de vida y biografías (Mallimaci \& Giménez-Béliveau, 2006) de los y las jóvenes a fin de reconstruir sus trayectorias, prácticas y sentidos como miembros de la ACA. La observación se realizó en espacios de participación juvenil con el fin de comprender y analizar las prácticas juveniles. Finalmente, se analizó material institucional para complementar los datos obtenidos con las técnicas mencionadas y reconstruir históricamente a la organización.

El universo de estudio se circunscribe a jóvenes varones y mujeres católicos de las localidades de Lanús y Ramos Mejía del Gran Buenos Aires³ y de provincias del interior

3 Lanús es una ciudad de la provincia de Buenos Aires creada en 1945 y ubicada a $11 \mathrm{~km}$ de la ciudad de Buenos Aires. La parroquia en la que se realizó el trabajo de campo se ubica en Lanús Este y los grupos de la Acción Católica funcionan en las instalaciones de un colegio parroquial. Ramos Mejía es una ciudad del partido de la Matanza creada en 1964 y ubicada en la zona oeste del Gran Buenos Aires, a $17 \mathrm{~km}$ de la ciudad de Buenos Aires. La parroquia en la que se realizó trabajo de campo se ubica a metros del centro de la ciudad y cuenta con un predio donde sólo se realizan actividades parroquiales. 
de Argentina. Por su parte, la muestra fue intencional. A partir de datos indicados por autoridades de la ACA, se realizó un primer rastreo por diócesis y localidades seleccionando aquellas parroquias con mayor disponibilidad de militantes y grupos juveniles.

En este trabajo serán considerados y consideradas jóvenes miembros de los denominados «grupos de militancia» 4 juveniles de la ACA. Para el análisis de este artículo, me basaré en el trabajo de campo realizado entre abril de 2016 y octubre de 2018 que consta de distintas etapas. Entre abril y junio de 2016 establecí el primer contacto con miembros de la ACA en la sede de la institución, donde mantuve charlas informales con referentes directivos y registré materiales institucionales en una biblioteca de acceso público. Entre julio y septiembre de 2016 realicé un primer contacto con miembros de la Dirección de Juventud y participé de diversas reuniones de planificación de los lineamientos institucionales para el área Juventud. En octubre de 2016 participé del Encuentro de Delegados en la provincia de Corrientes y de los ciclos de formación para militantes (Avellaneda, abril-octubre de 2017), donde establecí contacto con referentes parroquiales de amplia participación juvenil sugeridos por miembros directivos. De este modo, pude ampliar y complejizar la red de miembros de la ACA.

Finalmente, realicé una estancia de campo prolongada en una parroquia de Lanús (agosto de 2017 a febrero de 2018) y en una parroquia de Ramos Mejía (marzo 2018 a julio de 2018) donde se insertan grupos de la ACA de importante participación juvenil. Esto me permitió seleccionar jóvenes con una experiencia igual o mayor a dos años, ya que, pasado este tiempo, los y las jóvenes se convierten en miembros oficiales, militantes, y luego de cuatro años de permanencia en la institución pueden ser delegados de grupos.

De este modo, la muestra incluye a 12 jóvenes (seis varones y seis mujeres), entre $19 \mathrm{y}$ 31 años, militantes y delegados/as. ${ }^{5}$ Se excluyen de los casos aquellos jóvenes (hombres y mujeres) no «oficializados» en la ACA y sin experiencia en tareas directivas.

4 Los grupos de militancia son espacios de sociabilidad, formación religiosa y espiritual de la ACA. Los apostolados incluyen actividades solidarias como visitar hogares de niños y ancianos, villas, hospitales y cárceles, distribuir comida a personas en situación de calle y realizar tareas de alfabetización, entre otras. Para más información véase http://www.accioncatolica.org.ar/ http://jovenes.accioncatolica.org.ar/sobre-nosotros/ http://adultos.accioncatolica.org.ar/la-comision/sobre-nosotros/

${ }^{5}$ En mi investigación doctoral realicé 34 entrevistas a miembros de la ACA, 44 entrevistas a miembros de SAAC y diferentes instancias de observación participante en espacios directivos, asambleas y reuniones de las instituciones entre 2016 y 2020. Para este trabajo seleccioné un corpus de materiales reducido según los fines metodológicos del artículo, reservando el resto de los materiales para próximos trabajos. 
El trabajo de campo consta de observación participante y registros escritos tomados en eventos y actividades de los grupos mencionados; charlas informales con miembros directivos - jóvenes y adultos- de la ACA; y entrevistas en profundidad realizadas a jóvenes durante mi estadía en los grupos de militancia. Los nombres de los y las entrevistados mencionados en este trabajo son ficticios para preservar su anonimato. A este material de campo se añade el análisis de información disponible en el sitio web oficial de la ACA, documentos y bibliografía institucional. Además, se analizan fragmentos de la revista Crecer (1996-2019) destinada a las juventudes de la ACA.

Finalmente, para el análisis de los materiales de campo, se realizó una matriz de datos y un análisis temático de contenidos (Braun \& Clarke, 2006; Raigada, 2002) registrando aquellas palabras, temas y conceptos vinculados a lo juvenil, a fin de interpretar los modos en que la ACA construye juventud y las formas en que las juventudes católicas delinean sus propias trayectorias.

\section{Resultados}

\section{El proyecto católico en el siglo XX y el rol de las juventudes católicas}

La ACA es una asociación caracterizada por la participación del laicado en el apostolado jerárquico de la Iglesia, fundada ante un contexto de crisis social y política generalizado que favoreció su desarrollo. El llamado del Episcopado argentino a conformar una organización laical entendida como «brazo largo de las jerarquías eclesiales» permite advertir una relación directa y, en muchos casos, naturalizada de jóvenes y adultos con papas, obispos, sacerdotes y dirigentes católicos.

A principios del siglo XX los jóvenes eran percibidos por la Iglesia católica como agentes de transformación social. De este modo, se vinculaba la juventud a la fuerza, el heroísmo, la entrega, el martirio y el liderazgo político social y sindical para «recristianizar» a la sociedad argentina ${ }^{6}$ (Mallimaci, 1991). Sin embargo, la sociedad argentina y la Iglesia concebían a los jóvenes como una «fase en preparación, a mitad de camino entre la sujeción infantil y la plena inserción laboral» (Blanco, 2011, p. 142).

\footnotetext{
6 En esa época surgen organizaciones católicas juveniles que permiten advertir la capacidad de cambio atribuida a las juventudes, aunque buscarán moldearlas de acuerdo a los valores considerados moralmente «buenos» por los adultos.
} 
En 1931, la ACA se componía de centros (espacios destinados a los hombres) y de círculos (espacios destinados a las mujeres) que integraban las denominadas Ligas de Damas, Hombres y Juventud Femenina y la Federación de la Juventud Católica. Estas denominaciones se modificaron en 1937: los adultos de la ACA integraron respectivamente la Asociación de Mujeres de Acción Católica (AMAC) y la Asociación de Hombres de Acción Católica (AHAC). Las y los jóvenes, por su parte, integraron la Asociación de Jóvenes de Acción Católica (AJAC) y Jóvenes de Acción Católica (JAC).

Durante los primeros años, la ACA contó con un gran número de laicos provenientes de instituciones católicas fundadas desde fines del siglo XIX (Giménez-Béliveau, 2005). Sin embargo, entre los años cuarenta y sesenta la ACA experimentó un descenso relativo en el número de sus miembros y un envejecimiento de los mismos que fue percibido por las jerarquías católicas como consecuencia de la «seducción pagana de la sociedad a la que se dejaban llevar los jóvenes» (Acha, 2010, pp. 3-4). Esta percepción se correspondía con el modo en que los especialistas religiosos concebían a la juventud como etapa vital poco constructiva respecto a la adultez (Acha, 2010).

Debido a la disminución de miembros en la ACA, la institución introdujo las «ramas especializadas» por «ambientes» (no religiosos): laboral y profesional, empleados, estudiantes secundarios, universitarios y obreros (Blanco, 2011). En 1941 se creó la Juventud Obrera Católica (JOC), enfocada en la acción social de la institución, a diferencia de la formación de laicos que realizaban la JAC y la AJAC.

A lo largo de los años cincuenta se crearon la juventud estudiantil, universitaria y rural de la ACA (JEC, JUC, MRAC). Hacia fines de los años 1950, la ACA reconoció que la institución había envejecido, que tenían una «crisis de juventud» y que las prácticas de las mujeres se habían transformado.

El peronismo favoreció el aumento y la variación del consumo, el voto femenino y la multiplicación de los productos de los medios masivos de comunicación, produciendo transformaciones sociales en la moral sexual y familiar y en el activismo político-estudiantil (Cammarota, 2014, 2015; Cosse, 2011). Esto derivó en una crisis entre el peronismo y la Iglesia católica (Acha, 2010; Caimari, 1994). Sin embargo, esta crisis no explica la disminución de los y las jóvenes militantes en la ACA; dichas transformaciones sociales se articularon con dificultades institucionales internas (Acha, 2010; Cammarota, 2015). La ACA demandaba la internalización de una cultura apostólica rigurosa que atentaba contra la permanencia de los fieles dentro del apostolado y fue cuestionada por laicos que deman- 
daban una mayor flexibilidad de las estructuras institucionales sujetas a las jerarquías (Giménez-Béliveau, 2005).

De acuerdo con Acha (2010), Cammarota (2015), Lida (2013) y Lida y Mauro (2009) la lógica de la sociedad de masas, la entrada masiva de los trabajadores al mundo del consumo, la expansión de la educación secundaria, así como el acompañamiento de nuevas prácticas socioculturales minaron los lazos identitarios que ligaban a una parte de la juventud católica con la ACA. Este hecho expresaba, así mismo, que la verticalidad de la Iglesia católica (que partía del papado, continuaba en los obispos y terminaba en las parroquias) era más bien un ideal de la romanización que una realidad (Bianchi, 2002).

En los años setenta la ACA realizó un relanzamiento institucional, incorporando cambios en el laicado a partir del Concilio Vaticano II. Estos cambios estaban vinculados a una apertura al mundo, una atención preferencial por los pobres y un espíritu horizontal y participativo que remitía al compromiso histórico por la «liberación nacional y social», que se perfilaba como ideal para grandes sectores de la juventud argentina (Politi, 1992, p. 121, como es citado en Dominella, 2012).

Durante esos años, los movimientos católicos especializados se radicalizaron y fueron deslegitimados por las jerarquías, que negaban su relación con la ACA en los actos políticos de los movimientos. Este aspecto acentuó la disminución de militantes en universidades y escuelas. Así, las acciones católicas especializadas funcionaron como puertas de salida del catolicismo: los militantes se comprometían como cristianos en ámbitos laborales o educativos y, finalmente, cortaban los lazos con la ACA (en cuanto a su membrecía aunque no en relación a sus creencias y valores católicos) al consolidar sus compromisos sociales y políticos (Dominella, 2010; Donatello, 2010; Giménez-Béliveau, 2005).

En 1977 se disolvieron las ramas especializadas de la Acción Católica (JOC, JEC y JUC) debido a la politización de sus miembros, cambiando nuevamente sus denominaciones por $\mathrm{r}$-jvac (Rama de jóvenes varones de acción católica), R-jmac (Rama de jóvenes mujeres de acción católica), R-hac (Rama de hombres de acción católica) y R-mac (Rama de mujeres de acción católica). De este modo, las ramas se dedicaron a la formación católica de los y las militantes en las parroquias.

Finalmente, con el restablecimiento de la democracia en 1983, las jerarquías católicas otorgaron a la juventud un lugar central como etapa vital prolongada y muchos jóvenes de la ACA se insertaron en organizaciones partidarias y universitarias. 
En 1995, debido a la reducción de sus miembros, la ACA unificó las ramas e incorporó las denominadas «áreas» de «aspirantes», «jóvenes», «adultos» $\mathrm{y}$ «sectores» (Acha, 2016). Las tres primeras áreas tienen una inserción directa en parroquias mediante grupos de militancia de reunión periódica y están subdivididas en grupos etarios, mientras que el área «sectores» focaliza la militancia en espacios laborales, políticos y educativos de los y las militantes y ofrece charlas y actividades esporádicas para formar a sus miembros.

Entre los años 2010 y 2019 la ACA orientó las actividades de sus militantes en la difusión religiosa «desde el Evangelio de la vida, la familia, la inclusión social, la educación y el trabajo» (Acta de la $44^{\circ}$ Asamblea Federal de ACA, 17/4/2010) y en el trabajo «a favor de la vida, la familia, la libertad, la dignidad humana, el cuidado de la casa común, construyendo la amistad social» (Asamblea Federal, 2018). De esta Asamblea surgieron algunos elementos a destacar. Por un lado, la consideración del aborto como tema problemático para la institución, ante el cual sus militantes tomarían posiciones encontradas. Por otro, la postulación y futura elección de un miembro joven en el consejo directivo de la ACA. Esto no ocurría desde 1970 y respondió a un interés institucional por obtener una perspectiva más amplia sobre el aborto, tema que los adultos percibieron de interés e incidencia juvenil.

En lo que sigue, nos centraremos en las construcciones de juventud que la ACA produce en la actualidad, para luego avanzar en los posicionamientos de los y las jóvenes católicos respecto a dichas construcciones partiendo del análisis de sus trayectorias.

\section{Construcciones institucionales de juventud en la}

\section{Acción Católica Argentina}

Las juventudes de la ACA están constituidas por tramas materiales y simbólicas específicas (Pérez-Islas, 20oo), consideradas en este trabajo como producciones de la sociedad argentina poco exploradas por los estudios de juventud y de religiones (Chaves, 2009). En este apartado, nos centraremos en las construcciones de juventud delineadas institucionalmente por la ACA en la actualidad. Una vía para identificarlas es observar el modo en que la institución organiza a sus miembros en «grupos de militancia», diferenciándolos por edades y etapas vitales (tabla 1). 
Los grupos de militancia se emplazan en parroquias de distintas diócesis. ${ }^{7}$ A nivel nacional, cada área (tabla 1) es dirigida por una comisión integrada por dos responsables, un grupo de quince vocales y un sacerdote asesor de las parroquias en las que funciona la ACA.

\section{Tabla 1}

\section{Grupos etarios de la ACA}

\begin{tabular}{cccc}
\hline Edad & Área & Tipo de miembro & $\begin{array}{c}\text { Denominación } \\
\text { etaria nativa }\end{array}$ \\
\hline 6-8 & Aspirantes & Niños de Acción Católica & Niños \\
$9-10$ & Aspirantes & Aspirantes menores & Niños \\
$11-12$ & Aspirantes & Aspirantes mayores & Niños \\
$13-14$ & Jóvenes & Prejuveniles & Jóvenes \\
$15-17$ & Jóvenes & Juveniles & Jóvenes \\
$18-35$ & Jóvenes & Mayores & Jóvenes \\
$36-$ hasta & Adultos & Matrimonios, adultos, adultos- & Adultos \\
ancianidad & jóvenes, mujeres, abuelos & \\
\hline
\end{tabular}

Nota. Basado en los datos de página web oficial de la ACA.

Los grupos de militancia juveniles están conformados por miembros desde los 13 años hasta la edad en que «por situación o actividad laboral, profesional o matrimonial, experimenten una nueva realidad personal marcada por características propias de la adultez» (ACA, 2018a). Para la ACA, esta circunstancia puede verificarse entre los $25 \mathrm{y}$ los 35 años. Si bien se establece que a los 36 años los y las militantes dejan de ser jóvenes para convertirse en adultos, este margen es lábil según las diversas trayectorias: «como la Acción Católica se basa en acompañar al militante en todas las etapas de su vida, depende de la vida de cada uno cuándo pasa de un área a otra» (Milena, 22 años, militante de la ACA, Ramos Mejía, 24/3/2018).

Por su parte, los grupos de adultos se distribuyen en «adultos jóvenes», «medios»y «mayores» y están dirigidos a personas que «llegada la etapa de la adultez, desean realizar un camino de fe y misión en comunidad con las características propias de la identidad, carisma y ministerio de la Acción Católica» (ACA, 2018b). De este modo, es en la vida adulta donde el sujeto finalmente conforma su identidad institucional.

${ }^{7}$ División territorial realizada por la Iglesia católica conformada por varias localidades bajo la jurisdicción de un obispo. 
Las concepciones de juventud y adultez construidas por la institución influyen en el pasaje de las juventudes desde el grupo juvenil al de adultos. Un joven es adulto a los 36 años de edad y al desempeñar ciertas tareas consideradas como indicadores de pasaje a la adultez (Margulis \& Urresti, 1998) tales como trabajar, independizarse económicamente de sus padres o finalizar estudios terciarios o universitarios. Pero en la ACA, aunque un miembro de 36 años estudie y trabaje (aspectos considerados propios de la adultez), si aún no ha finalizado su carrera o no se ha casado, es considerado un/a joven por los/las miembros de la institución:

A los jóvenes les cuesta mucho cerrar etapas. Tenemos jóvenes que son eternos estudiantes que no se reciben nunca, al punto de que empiezan a trabajar porque tienen que sostener ellos sus estudios. (...) Cuesta ir finalizando etapas. Noviazgos muy largos también que vos decís, bueno, ya es momento [de casarse] o, al menos, hay que plantearse cerrar estas etapas también. (Sabrina, 31 años, miembro de la Comisión Nacional de Juventud, militante y dirigente de la ACA, Provincia de San Juan, 7/11/17)

La crítica de la dirigente indica algunos aspectos interesantes para analizar. Por un lado, la joven considera a las juventudes como dependientes económicamente de sus padres de manera generalizada. De este modo, Sabrina omite la participación de jóvenes trabajadores que también integran los grupos de militancia. Sobre este punto, es importante destacar que quienes tienen una participación activa en los grupos trabajan en oficinas o comercios durante la semana, a diferencia de aquellos y aquellas jóvenes que también trabajan los fines de semana y cuya participación en los grupos es esporádica, debido a sus limitaciones temporales. En estos últimos casos, los vínculos con sus pares se mantienen mediante contactos virtuales y encuentros vespertinos en cenas, fiestas, cumpleaños o salidas por fuera de los grupos de militancia.

Por otro lado, la joven expresa una necesidad institucional de que las juventudes finalicen la etapa de búsqueda y experimentación propia de su condición existencial juvenil (Margulis \& Urresti, 1998), realizando efectivamente un pasaje a la adultez mediante el «cierre de etapas». La obligatoriedad de formar noviazgos cuyo objetivo sea el matrimonio refiere a uno de los proyectos de vida ofrecidos por la institución y coincidente con lo propuesto por los especialistas religiosos. Este tipo de noviazgos constituye un espacio legítimo del ejercicio de la sexualidad de las juventudes a partir de «relaciones castas». Si bien la ACA contempla y presenta otros horizontes para la vida adulta — tales como las vocaciones religiosas y sacerdotales- estos no constituyen un tema abordado en pro- 
fundidad en los grupos de militancia ni en los objetivos formales propuestos para la rama juvenil, así como tampoco son de interés para la mayoría de los/las jóvenes.

Además, en el relato de Sabrina se observa una valoración institucional de la adultez como etapa vital más constructiva y fructífera que la juventud, en continuidad con las concepciones institucionales de juventud producidas entre los años cincuenta y sesenta.

La elección de trayectorias diversas y no lineales es entendida por los dirigentes y especialistas religiosos de la ACA como una «dificultad juvenil» de asumir compromisos laborales, profesiones o vinculares y, en definitiva, como una incapacidad de convertirse en adultos. Además, la ACA incluye otros elementos característicos de este tipo de institución católica para que el pasaje a la adultez sea legítimo: la conformación de parejas heterosexuales, el casamiento por la Iglesia (ya mencionado), la descendencia y la transmisión religiosa a los hijos e hijas y al resto de la sociedad (mediante la realización de tareas de apostolado y la coordinación de grupos de militancia). Así mismo, el relato de Sabrina responde al modo institucional de percibir las trayectorias juveniles e indica que una persona continua siendo joven si no cumple con ciertas responsabilidades identificadas por la institución, dando por supuesto que todos y todas las jóvenes transitan una moratoria social. ${ }^{8}$

En las definiciones producidas desde la ACA predomina una idea de juventud como una etapa incompleta en tránsito evolutivo hacia la adultez, donde los sujetos asumen las responsabilidades consideradas importantes. Por ello, en la ACA prevalece una perspectiva adultocéntrica que ubica al mundo adulto como destino final. De esta manera, el joven es considerado como un sujeto incompleto en relación al adulto (Serrano-Amaya, 2002). De acuerdo con Alvarado et al. (2009):

El adultocentrismo, considerado como la hegemonía de la interpretación del mundo desde la postura del sujeto adulto/masculino/occidental, opera, de un lado, como un dispositivo de control social que establece relaciones de dominio centro-periferia para definir a los sujetos, siendo la periferia aquello que no encaja con el modelo de ser adulto y que permite la ilusión de un modelo evolutivo en el desarrollo psicológico de los sujetos, en donde la juventud aparece como un tránsito a la adultez y por tanto un sujeto que «está siendo sin ser», y de otro, como una moratoria social en la cual el sujeto es desrresponsabilizado y ubicado en el escenario del ocio «privilegiado» o en la condición del «no futuro» (p. 96).

8 La moratoria social es una etapa que atraviesan ciertos y ciertas jóvenes de clase media en la cual son desrresponsabilizados de tareas propias del mundo adulto y ubicados en un escenario de ocio privilegiado. 
Las definiciones institucionales de juventud no concuerdan con las realidades experimentadas por los y las jóvenes de la ACA, quienes asumen diversos compromisos en sus vidas cotidianas (estudio de carreras terciarias y universitarias, trabajos, coordinación de grupos de militancia, tareas de apostolado, organización de eventos parroquiales y diocesanos, entre otros).

La construcción institucional de juventud es mencionada en reiteradas publicaciones de la revista Crecer $^{9}$ y es representada mediante fotografías de jóvenes esposos, esposas, padres y madres de familia. A los y las jóvenes que cumplen con el modelo católico, se los denomina «jóvenes-adultos»o «adultos-jóvenes». De esta manera, se señala que el y la joven se encuentran en tránsito hacia la adultez como etapa deseada y superior a la juventud. También es una forma de indicar que, aun perteneciendo al área de adultos, se les considera más jóvenes que los adultos medios y que los adultos mayores de la institución.

Por otro lado, es interesante advertir el lugar otorgado a los hombres adultos de la ACA, los asesores religiosos y los Sumos Pontífices, al momento de definir el «ser joven cristiano» esperado por la ACA:

El asesor religioso de jóvenes [sacerdote] perfila nuestro «ser joven cristiano» diciendo: Un joven de verdadera identidad católica es aquél que en casa apoya a la familia; en la escuela se esfuerza por estudiar. Con la novia o el novio busca todos los medios para vivir con santidad esta etapa importante de la vida [castidad]. (...) Aquel que consigue ver con los ojos de la fe los problemas sociales, familiares, psicológicos y las dificultades. (Crecer, sección Espacio joven, 2012, nº 61, pp. 6-7)

La oración es algo imprescindible en la vida de todo cristiano para ir caminando en esa maduración interior que como adultos estamos transitando. (...) Una vez que vemos que la fe está firme, la empezamos a proclamar especialmente en nuestros hijos. Los adultos jóvenes (AJ) que rezan en familia, que estudian su fe, que comparten un apostolado, tienen como modelo a la Sagrada Familia de Nazaret y buscan trasmitir ese amor a todo su entorno. (Crecer, sección Familia, 2013, nº 65, pp. 6-7)

En los fragmentos citados, el y la joven ideal cumplen sus deberes de hijo/a, estudiante, novio/a, ciudadano/a y cristiano/a. La oración es parte integrante de la identidad de los miembros «maduros» de la institución, constituyendo una práctica fundamental para

9 Se han revisado 74 números de la revista desde el año 1996 hasta la actualidad (año 2019). La revista está dirigida a los/las jóvenes de la ACA, aunque no tiene una importante difusión debido al escaso número de ejemplares impresos. Sin embargo, permite analizar las construcciones de juventud producidas por los adultos de la institución. 
la vida adulta del militante. Además, el adulto-joven debe ser una persona con «verdadera identidad católica» que se mantenga casto con su pareja hasta el matrimonio y que evangelice como formas de practicar la caridad. Así mismo, cuando un joven asume las responsabilidades consideradas importantes por la ACA, debe formar una familia (nuclear tradicional) y gestar una descendencia a la cual transmita la religión católica. La mención a la familia, indica el rol central que tienen los niños y niñas para la ACA, considerados como «semillas del reino de Dios».10 Luego de cumplir con estas responsabilidades, la institución motiva a que los casados y las casadas realicen tareas apostólicas en las parroquias.

La trayectoria ideal propuesta por la ACA es entendida como un proyecto de vida que los y las jóvenes deben desarrollar mediante un discernimiento. Para ello, cuentan con la figura de un acompañante (experto en el tema debido a su mayor experiencia institucional), quien los orienta en su proyecto:

Como nos dice el papa Francisco: este es el proyecto de Dios para los hombres y mujeres de todos los tiempos (...) sin excepción. (Papa Francisco, 2017, como es citado en ACA, s. f.)

El proyecto personal de vida cristiana es una de las herramientas que la Acción Católica utiliza en la formación y crecimiento cristiano de jóvenes. Con ella pretendemos ayudarlos a integrar su fe, su vida y el mundo, partiendo de su propia realidad. Es hacer que el sueño de Dios se haga carne y presencia activa en nuestras vidas cotidianas. (ACA, s. f.)

Queremos proponer a nuestros Jóvenes iniciar un camino, un proceso de discernimiento en el que puedan replantearse de forma responsable la Construcción de un Proyecto de Vida, generando espacios que favorezcan el encuentro personal con Jesús, quien nos guía, nos acerca a la verdad y nos ayuda a alcanzar la plenitud. Es un itinerario que acompaña la vida de los Jóvenes desde la adolescencia hasta la vida adulta. (ACA, 2008)

Para los especialistas religiosos el proyecto de vida representa un «plan querido y pensado por Dios» de carácter universal. Por ello, podría aplicarse a todas las juventudes sin distinción. Además, la noción de proyecto de vida denota una concepción de las trayectorias como recorridos lineales y sin interferencias, desde una percepción de la vida social y personal ordenada y regulada por Dios. Así mismo, con esta noción se advierte un control y agencia de las juventudes sobre sus trayectorias desde su libre albedrío. De este modo, la institución omite el contexto social y económico más amplio: las dificultades

${ }^{10}$ Fragmento de entrevista realizada a Damián, 30 años, militante, delegado y miembro de la Comisión Nacional de Juventud de ACA, San Juan, 14/10/18. 
de las juventudes para conseguir trabajos, las crisis y las transformaciones sociales no parecen constituir para la ACA dimensiones que interfieran en las trayectorias de los y las jóvenes. Por tanto, existe una posición institucional anacrónica que se inscribe en las primeras décadas del siglo XX al momento de su fundación.

\section{Trayectorias militantes católicas en el siglo XXI}

En este apartado se presentan los modos en que se adoptan o resignifican las construcciones institucionales de juventud a partir de las percepciones y trayectorias militantes de las juventudes católicas.

En las parroquias, los y las jóvenes construyen sus propias denominaciones de los grupos de militancia de acuerdo a sus realidades sociales. Estas se diferencian de las propuestas institucionales y permiten observar trayectorias diversas experimentadas por las juventudes católicas (tablas 2 y 3).

Sobre estos datos pueden señalarse algunos aspectos centrales. Los grupos de niños y niñas de la parroquia de Lanús (tabla 2 ) incluyen miembros desde los cinco años, una edad menor a la propuesta por la ACA, que es de seis años (tabla 1). Por su parte, en la parroquia de Ramos Mejía (tabla 3), los y las militantes conservan casi la misma distribución en los grupos de niños y niñas, aunque reúnen a todos los y las integrantes de entre seis y diez $u$ once años en aspirantes menores y aspirantes mayores.

\section{Tabla 2}

\section{Grupos etarios en ACA (Lanús)}

\begin{tabular}{ccc}
\hline Edad & Tipo de miembro & $\begin{array}{c}\text { Denominación } \\
\text { etaria nativa }\end{array}$ \\
\hline $5-10$ & Aspirantes & Niños \\
$11-12$ & Pre-prejuveniles («Pre-Pre») & Niños \\
$13-14$ & Prejuveniles & Niños \\
$15-16$ & Juveniles menores («JuMe») & Jóvenes \\
$17-18$ & Juveniles mayores («JuMa») & Jóvenes \\
$19-20$ & Premayores & Jóvenes \\
21 en adelante & Jóvenes mayores («JoMa») & Jóvenes \\
\hline
\end{tabular}

Nota. Basado en los datos obtenidos en registros de trabajo de campo. 
Los grupos que presentan mayor diversidad son los juveniles. Esto responde a que en la parroquia (tabla 2) los adultos participan de otras organizaciones católicas o comunidades parroquiales, ${ }^{11} \mathrm{y}$ a que fue un joven quien difundió la ACA allí, logrando mayor participación de sus pares y amigos. De este modo, se registraron cinco grupos juveniles a diferencia de los tres propuestos institucionalmente.

\section{Tabla 3}

Grupos etarios en ACA (Ramos Mejía)

\begin{tabular}{ccc}
\hline Edad & Tipo de miembro & $\begin{array}{c}\text { Denominación } \\
\text { etaria nativa }\end{array}$ \\
\hline $6-8$ & Aspirantes menores & Niños \\
$9-10 / 11$ & Aspirantes mayores & Niños \\
$11 / 12-15$ & Prejuveniles & Jóvenes \\
$15 / 16-18$ & Juveniles & Jóvenes \\
$18 / 19-25$ & Mayores & Jóvenes \\
& Adultos-jóvenes & Adultos \\
$25-35$ & («Generación intermedia») & Adultos \\
\hline
\end{tabular}

Nota. Basado en los datos obtenidos en registros de trabajo de campo.

Por su parte, en la tabla 3 podemos observar que las ramas juveniles incluyen a miembros de entre 11/12 y 25 años. En este caso, el pasaje a la adultez se produciría alrededor de los 26 años. En la parroquia de Ramos Mejía funcionan los grupos adultos jóvenes y adultos mayores. De este último participan los miembros fundadores de los grupos de militancia y del grupo adultos jóvenes, quienes tienen entre 26 y 35 años de edad. En distintos espacios de sociabilidad, las juventudes se referían de manera informal a adultos jóvenes como «Ge-i» o generación intermedia. Al consultarles los motivos de estas denominaciones, indicaron que «es una forma graciosa de remarcar que somos parte de una generación intermedia; no queremos estar en el grupo de adultos porque no nos sentimos adultos» (Ignacio, 28 años, militante y delegado de la ACA, Ramos Mejía, 24/3/18). Desde esta perspectiva, el grupo generación intermedia estaría ubicado entre los grupos de jóvenes y adultos e indicaría una ampliación de la condición juvenil. Así mismo, en char-

${ }^{11}$ Tales como el Movimiento de la Palabra de Dios o un grupo de oración de devotos de la Virgen de Lanús. Para más información sobre estas organizaciones, véase: http://www.mopal.org/es/ident/index.htm y http://www.virgendelanus.com.ar/web/historia.htm 
las informales con mujeres militantes, ellas mencionaron que no querían ser adultas, ya que este pasaje implicaba tener hijos y casarse, opciones alejadas de sus propios proyectos personales como seguir estudiando o realizar viajes. De este modo, las jóvenes planteaban una posición contraria al modelo de adulto-joven propuesto institucionalmente a partir de los propios recorridos facilitados por su posición de clase social media.

Respecto a la formación de noviazgos castos, este no era un tema que representara mayores preocupaciones entre las juventudes. Si bien, la ACA propone este tipo de relaciones, entre los y las jóvenes se encontraban quienes optaban por mantener relaciones sexuales prematrimoniales, aspecto que no producía un quiebre en sus trayectorias como militantes católicos.

Finalmente, cabe destacar que la denominación informal de los grupos de militancia de ambas parroquias («JuMe», «JuMa», «JoMa», «Ge-i») denota la familiaridad, afecto y cercanía que las juventudes mantienen con los grupos como espacios de sociabilidad e identificación fundamentales en sus trayectorias, y como un modo particular de transitar la juventud que incluye las creencias y prácticas católicas:

ACA es una institución por la que nos hemos sacrificado un montón. Yo a los cumpleaños de mis amigas llego tarde y a la que me dice algo, la mando a cagar; es así, ya saben. Al principio me decían: «No, bueno, vos siempre llegás tarde», «Bueno, si no te gusta, no voy». (Emilia, 25 años, responsable de jóvenes de ACA en parroquia de Ramos Mejía, 7/4/18)

La Acción Católica es como una segunda casa. Yo estoy desde muy chico acá, mis amigos y mi familia están acá. Es como una casa más grande. Vos podés tener un problema de fe y te sostiene una familia. Acá conocí a mis segundos viejos que son Susana y Jorge a quienes conozco de muy chiquito. (Marcos, 23 años, militante y delegado de ACA, Ramos Mejía, $24 / 3 / 18)$

Muchos adultos de la parroquia apadrinan a niños, niñas y jóvenes en sus ceremonias de «promesa»y «oficialización», ${ }^{12}$ lo que genera una especie de «familia católica» cuyos lazos y vínculos son mucho más sólidos que los que mantienen algunos y algunas jóvenes con sus familias biológicas. Dominella (2019) ha señalado la importancia de las emociones y los afectos en los ingresos y permanencias de las juventudes en las ramas de la ACA entre 1960 y 1970, aspectos que pueden vincularse a los grupos juveniles contemporáneos

${ }^{12}$ La promesa (para menores de edad) o la oficialización (para mayores de edad) son ritos de iniciación que realizan quienes ingresan a la ACA, instituyéndolos/las como miembros oficiales y militantes. Además, estos ritos denotan el compromiso que los sujetos establecen con la ACA por el resto de sus vidas. 
de la institución. La autora menciona cómo estos espacios son percibidos como grupos familiares debido a que los y las militantes comparten mucho tiempo en la institución y forman vínculos de amistad, compañerismo, noviazgos y matrimonios entre ellos y ellas.

El análisis de las percepciones y las trayectorias juveniles permite advertir de qué manera son percibidos los modelos de adulto-joven entre los y las jóvenes. Algunos y algunas siguen lo propuesto por la ACA pero, en otros casos, las juventudes forman parejas homosexuales, no desean tener hijos (como se señaló anteriormente), no finalizan sus estudios (terciarios o universitarios) porque deben trabajar o encuentran dificultades para conseguir trabajos estables:

En mi caso es controversial porque yo, la primera etapa de mi vida fui heterosexual y ahora soy homosexual. (...) No creo que te haga ser menos católico tener otra elección de vida; para mí, siendo católico, siendo ateo, siendo agnóstico, si vos sos feliz y no molestás al resto de las personas, contribuís a la sociedad siendo mejor. (...) Era lo que quería Jesús, el amor; no importa la forma que tenga el amor, el objetivo es amarse a uno mismo y amar al prójimo. A mí me costó mucho el tema por la mirada que pudieran tener los padres de los militantes, el cura, el miedo de que me puedan echar de la parroquia. (...) Pero no aclaré absolutamente nada porque tampoco creo que es necesario que una persona esté dando explicaciones porque uno no tiene la culpa de nada, no se mandó ninguna como para decir: -mirá, necesito tu aceptación. (Matías, militante y delegado de la ACA, 26 años, 23/12/17, se omite localidad para preservar la identidad del joven)

La Acción Católica ha tenido que organizarse, caerse, levantarse a medida que la sociedad fue cambiando y creo que la iglesia tiene que acompañar ese cambio, o sea, militantes gays hemos tenido, ¿dónde están? No, no están, se van. (Lautaro, militante y delegado de ACA, 27 años, Lanús, 21/4/18)

En Acción Católica no puede venir una pareja homosexual a una misa, por ejemplo. Lo cierto es que hemos tenido militantes gays que se han ido, algunos por sentirse excluidos; pero no se ha sentido esto del párroco, no te va a negar la comunión. (...) Gracias a Dios tuvimos un párroco de 10 porque entiende la sociedad de hoy. Pero en un montón de otras Acciones Católicas al militante homosexual no le van a decir que es un enfermo, pero le van a decir que no está en el plan de Dios o van a tratar de convencerlo. (Juan, 30 años, militante y delegado de ACA, Lanús, 3/3/18)

El modelo juvenil propuesto por la ACA se transmite en los grupos de militancia como un camino ideal en tránsito hacia la adultez. Sin embargo, en las parroquias se observaron otras formas de percibir y de transitar la juventud como etapa vital. Estas 
formas emergieron a partir de los cambios sociales, culturales y políticos producidos en el contexto local argentino durante las últimas décadas, en torno a la ley del matrimonio igualitario (2010) y los debates sobre la interrupción voluntaria del embarazo (2018) que interpelaron a las juventudes. Así mismo, las percepciones de los y las jóvenes se vinculan a las limitaciones sociales a las que se enfrentan para conseguir trabajos estables que, entre otros aspectos, permean y complejizan las identidades y las diversas trayectorias delineadas dentro y fuera de la ACA.

Estas trayectorias no siempre se ajustan a las conductas, valores, normas, prácticas y percepciones emanadas de la Iglesia católica y sus especialistas, aspecto que deriva en ciertas tensiones producidas entre jóvenes que cuestionan su permanencia en la ACA. De todas formas, entre aquellos que permanecen en la institución prevalece el sentido que para ellos y ellas tienen los valores católicos (caridad, servicio al prójimo, amor a Cristo) y el desempeño de distintos roles directivos para transmitir dichos valores.

Al momento de consultarles sobre sus trayectorias, expresaban sus percepciones respecto a los debates en torno al aborto como un aspecto que los y las interpelaba:

Yo estoy a favor del aborto porque creo que si una persona toma la decisión de no tener un hijo es súper respetable y tampoco creo que haya que culpabilizar a esa persona. (...) En la iglesia siempre se pensó de otra manera y ahora uno llega y piensa de otra forma. (...) A veces creo que pienso una cosa e igual sigo yendo a la parroquia; pero creo que es cuestión de saber llevar los dos pensamientos para el mismo lado. (...) parece que no va de la mano ser católica y estar a favor del aborto, pero necesito que vaya de la mano. (Lucía, 19 años, militante y delegada de la ACA, Lanús, 24/2/18)

Yo la estoy pasando para el culo con el tema del aborto en las redes sociales, pero yo tampoco me la juego. Vos me podés decir no ponés nada en tu Facebook defendiendo [las dos vidas] pero no tengo ganas de que nadie me comente nada y pelearme y, por eso, estoy tomando esta postura de mierda y sé que la iglesia debiera tomar otra postura. Va a haber un movimiento en contra [del aborto] pero yo no tengo ganas de ir porque estoy cansada de la politización, de que haya persecución y violencia. (Carla, 27 años, presidenta de la ACA en parroquia de Ramos Mejía, 7/3/18)

Las opiniones son distintas y, sin embargo, todos compartimos un mismo lugar que es la parroquia. Entonces, no quiere decir que vos porque estés adentro de la Acción Católica o de la iglesia pienses de una manera, esa gente que lo dice, no conoce nada del tema. (Esteban, 21 años, militante y delegado de la ACA, Ramos Mejía, 24/3/18) 
En el primer caso, Lucía estudia Trabajo Social. Durante la entrevista mencionó que hacía poco tiempo había cambiado su percepción cuando una amiga tuvo que practicarse un aborto, experiencia que la había «movilizado» profundamente.

Carla es estudiante de Medicina. Toda su familia milita en la ACA y sus padres fundaron el primer grupo de militancia en la parroquia de Ramos Mejía. Aquí, la relación entre jóvenes y adultos está marcada por una fuerte impronta de las propuestas y directivas emanadas de la Iglesia católica sobre los debates y las transformaciones sociales, con escasos márgenes para la disidencia del joven laicado. Siguiendo a Margulis y Urresti (1998) la categoría de juventud «es un significante complejo que contiene múltiples modalidades que llevan a procesar socialmente la condición de edad, tomando en cuenta la diferenciación social, la inserción en la familia y en otras instituciones» (p. 1). Por ello, el tránsito de las juventudes en la ACA supone considerar posicionamientos diversos, complejos y limitados durante un período de tiempo que se presenta como breve y en construcción.

Estas heterogeneidades en las trayectorias juveniles debido a su participación simultánea en instituciones laicas y católicas, en muchos casos derivan en fuertes cuestionamientos a las propuestas de las jerarquías eclesiales. Sin embargo, entre los y las jóvenes se reconoce un interés por continuar desempeñando tareas directivas en la ACA. En este sentido, es posible encontrar una diferenciación que realizan las juventudes entre las jerarquías y el trabajo de base realizado en las parroquias, en pos de ciertos valores católicos como la caridad, el servicio y la comunidad, y los vínculos con militantes.

A la vez, se han observado trayectorias de jóvenes que abandonaron la ACA al reconocer fuertes limitaciones institucionales en el tratamiento de temas de su interés (aborto, homosexualidad, relaciones prematrimoniales, participación de las mujeres en espacios directivos, entre otros). Esto se observó sobre todo entre jóvenes provenientes de distintas carreras del campo de las Ciencias Sociales y las Humanidades, las cuales les permitieron repensar sus prácticas a partir de su formación y práctica profesional.

Finalmente, algunas trayectorias católicas cruzadas con trayectorias universitarias encuentran sus límites, como en el caso de la siguiente entrevistada quien abandonó la carrera de Comunicación Social al entender que los contenidos que le presentaban se enfrentaban a sus ideales y creencias:

Yo estoy ahora en una facultad recontra política. (...) Tiene mucho de que vos lo olés. ¿Viste cuando en la clase, el profesor entre líneas te va tirando bajadas? Esas son cosas que me llevaron a alejarme de la carrera porque yo puedo generar mis propias ideas a partir de 
mi propia experiencia; no necesito que otro me baje las suyas. (Paula, 27 años, militante y delegada de la ACA, Ramos Mejía, 7/4/18)

Si bien la Iglesia católica propone definiciones y horizontes de sentido para los y las creyentes, estos resignifican las propuestas institucionales desde sus propias experiencias, dando cuenta de márgenes, fronteras, disidencias y heterogeneidades al interior del catolicismo (Giménez-Béliveau, 2016). De modo que en la ACA no se advierten identidades juveniles cerradas sobre sí mismas, sino identificaciones que incluyen características mixtas: católicas y laicas. Estas permiten el tránsito simultáneo de las juventudes por instituciones religiosas y civiles, con concepciones de la realidad social de los sujetos, de las corporalidades y de las prácticas contrarias entre sí —en diversos casos-, pero que conviven como formatos desde los cuales las juventudes se posicionan en la sociedad argentina contemporánea trazando sus propios recorridos.

\section{Discusión}

En este artículo se abordaron las construcciones de juventud y las trayectorias de jóvenes militantes católicos y católicas. En la actualidad, la ACA reúne a miles de jóvenes que encuentran en ella un lugar propicio para ser joven y vivir la juventud, aunque delineando sus propias trayectorias no siempre acordes a las propuestas institucionales. Este trabajo permite reconocer otros modos de construir y de vivir la juventud a partir de la inserción de jóvenes en instituciones católicas situadas en parroquias del Gran Buenos Aires.

El análisis de discursos, documentos y materiales de la ACA referidos a las juventudes permitieron rastrear construcciones de juventud provenientes de los especialistas religiosos. Estas responden a un formato anacrónico de juventud delineado a principios del siglo XX (Acha, 2010) como espacio vital donde prevalecen la austeridad y el sacrificio por sobre el placer y la experimentación de los sujetos (Dominella, 2018). Un interrogante que surge de este artículo es el alcance e influencia de la ACA sobre otros grupos poblacionales que no participan de espacios directivos y sobre otras instituciones vinculadas a los grados más altos de los especialistas religiosos (obispos, arzobispos y Sumos Pontífices), más allá de la analizada en este trabajo, en el contexto local e internacional.

Señaladas estas limitaciones, consideramos que en línea con los trabajos de Blanco (2008, 2011) y Cammarota (2017), la ACA asocia la juventud con la posibilidad de cambio, vitalidad, fortaleza espiritual y mayor disponibilidad de tiempo que los adultos, en 
tanto ello se oriente a desarrollar el proyecto juvenil propuesto por la Iglesia católica. La institución propone un modelo juvenil universal mediante la concreción de un proyecto de vida en el que las juventudes deben cumplir con ciertas pautas para convertirse en adultos: casarse por iglesia con una pareja heterosexual, ser padres y madres, transmitir la fe católica a sus familias, a la iglesia y a la sociedad. La ACA prepara a los y las jóvenes para desempeñarse en todos esos ámbitos a lo largo de su permanencia en los grupos de militancia donde se forman como militantes y delegados/as. Si bien, muchos de ellos y ellas intentan cumplir dicho modelo, se advierten tensiones entre las construcciones de juventud propuestas por la ACA y las trayectorias trazadas por algunos de ellos al interior de la institución, quienes experimentan otros modos de ser y de vivir sus juventudes distintos a los propuestos por la ACA. Estos modos se configuran a partir de las reflexiones y experiencias habilitadas en otros espacios sociales (universitarios, laborales, profesionales), en su interacción con otros y otras jóvenes (católicos y no católicos), y a partir de cambios sociales y culturales producidos en la sociedad argentina en las últimas décadas, los cuales están vinculados a los debates en torno al aborto, la ley de matrimonio igualitario y las dificultades que enfrentan las juventudes para insertarse en espacios laborales.

Con sus definiciones de juventud, la ACA parece cerrarse sobre sí misma como institución, entendiendo que una transformación de las juventudes solo es posible en pos de perfeccionar y concretar el proyecto católico integral también en el siglo XXI. Por ello, otros recorridos opuestos al católico son señalados y reencauzados institucionalmente. En algunos casos, el ocultamiento de trayectorias contrarias al modelo institucional por parte de las juventudes es una vía para continuar desempeñando actividades directivas y para no ser sancionadas por la institución. Retomando lo trabajado por Mosqueira (2014) para el caso evangélico-pentecostal, en la ACA es posible advertir dos modos de concebir a las juventudes: desde un «polo activo» vinculado a las juventudes católicas que perfilan el proyecto católico en tanto agentes de cambio social y seres del futuro, y desde un «polo pasivo» donde las trayectorias de jóvenes no católicos contrarias al formato eclesial son concebidas como peligrosas, incompletas o moralmente reencausables. En función de estas últimas, la Iglesia católica exhorta a las juventudes a transitar un proceso de transformación subjetiva hacia su «santificación».

Por lo expuesto, podemos concluir que si bien la ACA se propone estructurar la percepción de los y las jóvenes creyentes, estableciendo definiciones y horizontes de sentido para ellos y ellas, las propias elecciones y experiencias de las juventudes expresan márgenes, fronteras, disidencias y heterogeneidades dentro del catolicismo contemporáneo argentino. 


\section{Agradecimientos}

Agradezco al Consejo Nacional de Investigaciones Científicas y Técnicas (Conicet), al Programa Sociedad, Cultura y Religión del Centro de Estudios e Investigaciones Laborales (CEIL) y a los y las militantes de la Acción Católica Argentina que permitieron que realizara mi investigación y me brindaron su tiempo, relatos y trayectorias.

\section{Referencias}

Acción Católica Argentina. (1931). Carta pastoral colectiva del episcopado argentino sobre la Acción Católica. Autor.

Acción Católica Argentina. (2008). Proyecto de vida. 1. Fundamentación. Área jóvenes de Acción Católica. Autor.

Acción Católica Argentina. (s.f.). Acompañar. Material para el Acompañante. Estugraf.

Acción Católica Argentina. (2018a). Jóvenes de Acción Católica. Sobre nosotros. Recuperado el 20 de septiembre de 2018 desde http://jovenes.accioncatolica.org.ar/sobrenosotros

Acción Católica Argentina. (2018b). Adultos de Acción Católica. Sobre nosotros. Recuperado el 18 de septiembre de 2018 desde http://adultos.accioncatolica.org.ar/la-comision/ sobrenosotros

Acha, O. (2010). Tendencias de la afiliación en la Acción Católica Argentina (1931-1960). Travesía. Revista de historia económica y social, (12), 1-10.

Acha, O. (2011). Activismo y sociabilidad en las jóvenes de la Acción Católica en la ciudad de Buenos Aires (1930-1945). Cuadernos de Historia. Serie Economía y Sociedad, (12), 11-33.

Acha, O. (2016). La rama masculina juvenil de la Acción Católica Argentina: catolicismo y política asociativa (1931-1970). Revista Brasileira de História das Religiões, 9(25), 89-120. https://doi.org/10.4025/rbhranpuh.vgi25.31087

Alvarado, S. V., Posada, J., \& Gaviria, D. (2009). Contextualización teórica al tema de las juventudes: una mirada desde las ciencias sociales a la juventud. Revista Latinoamericana de Ciencias sociales, Niñez y Juventud, 7(1), 83-102.

Bianchi, S. (2002). La conformación de la Iglesia católica como actor político-social. Los laicos en la institución eclesiástica: las organizaciones de élite (1930-1950). Anuario IEHS, (17), 143-162. 
Bidegain, A. M. (2009). Participación y protagonismo de las mujeres en la historia del catolicismo latinoamericano. San Benito.

Blanco, J. (2008). Componentes identitarios del imaginario de la Juventud Obrera Católica. Cuadernos de Historia. Serie economía y Sociedad, (10), 83-118.

Blanco, J. (2011). Las distintas juventudes de la Iglesia en Argentina a mediados del siglo XX. Letras Históricas, (4),139-160.

Bottinelli, L., Bisaro, E., Ferreiroa, V., Gentile, F., Makón, A., \& Grojethovich, M. (2001). La JOC: el retorno de Cristo obrero. En F. Mallimaci, \& R. Di Stefano, (Comps.), Religión e imaginario social. Manantial.

Bourdieu, P. (1992). ¿Qué significa hablar? Akal.

Braslavsky, C. (1986). La juventud argentina: informe de situación. CEAL.

Braun, V. \& Clarke, V. (2006). Using thematic analysis in psychology. Qualitative Research in Psychology, 3(2), 77-101. https://doi.org/10.1191/1478088706qpo630a

Caimari, L. (1994). Perón y la Iglesia católica: religión, Estado y sociedad en la Argentina (1943-1955). Ariel.

Cammarota, A. (2014). Percepción de crisis y movilización juvenil en el sistema escolar argentino, 1950-1960. Kairos. Revista de Temas Sociales, 18(34), 1-19.

Cammarota, A. (2015). Soldados de Cristo Rey: notas sobre la cultura y la crisis del apostolado en la Juventud de Acción Católica (1940-1955). Revista de Estudios Sociales Contemporáneos, (12), 209-228.

Cammarota, A. (2017). Jefe, delegado, aspirante y grupo en la Juventud de Acción Católica Argentina (JAC): 1940-1950. Apuntes, 44(80), 79-104. https://doi.org/10.21678/ apuntes.80.905

Cattogio, M. S. (2010a). Contestatarios, mártires y herederos: sociabilidades político-religiosas $y$ ascesis altruista del catolicismo argentino en la dictadura y posdictadura [Tesis doctoral no publicada]. Universidad de Buenos Aires.

Catoggio, M. S. (2010b). Cambio de hábito: trayectorias de religiosas durante la última dictadura militar argentina. Latin American Research Review, 45(2), 27-48.

Cosse, I. (2011). Pareja, sexualidad y familia en los años sesenta: una revolución discreta en Buenos Aires. Siglo XXI.

Chaves, M. (2009). Investigaciones sobre juventudes en la Argentina: estado del arte en Ciencias Sociales, 1983-2006. Papeles de Trabajo, (5), 1-111.

Dominella, V. (2010). El fermento en la masa: la juventud universitaria católica en Bahía Blanca, entre la efervescencia política y la oleada represiva de la Triple A (1968-1975) [Tesis de Licenciatura no publicada]. Universidad Nacional del Sur. 
Dominella, V. (2012). Memorias de la militancia y la violencia política de integrantes de la Juventud Universitaria Católica en Bahía Blanca (1968-1975). Sociedad y Religión: Sociología, Antropología e Historia de la Religión en el Cono Sur, 22(37), 12-54.

Dominella, V. (2015). Espacios de sociabilidad: redes sociales de la renovación católica y militancia contestataria en Bahía Blanca (Argentina), entre 1968 y 1975. Revista Cultura y Religión, 9(1), 102-128.

Dominella, V. (2018). De la «revisión de vida» al despertar del compromiso cristiano contestatario. Las ramas especializadas de Acción Católica en Bahía Blanca (Argentina), 1967-1975. Estudos de Religiao, 32(2), 163-19o. https://doi.org/10.15603/2176-1078/ er.v32n2p163-190

Dominella, V. (2019). Afectividad, fe religiosa y militancia contestataria en las ramas especializadas de Acción Católica en Bahía Blanca (1967-1975). Pasado Abierto, 4(9), 175-199.

Donatello, L. M. (2010). Catolicismo y montoneros: religión, política y desencanto. Manantial.

Dubet, F. (2010). Sociología de la experiencia. Centro de Estudios Sociológicos.

Fora, M. (2002). Adolescentes y catolicismo: los grupos juveniles en la ciudad de La Plata: aproximación al estudio de la identidad religiosa. Gaceta de Antropología, (18).

Giménez-Béliveau, V. (2005). Sociabilidades de los laicos en el catolicismo en la Argentina: un recorrido socio-histórico. Prismas, Revista de Historia Intelectual, (9), 217-227.

Giménez-Béliveau, V. (2016). Católicos militantes: sujeto, comunidad e institución en la Argentina. Eudeba.

Guber, R. (2001). La etnografía: método, campo y reflexividad. Norma.

Larrondo, M. \& Vommaro, P. (2013). Juventudes y participación política en los últimos treinta años de democracia en la Argentina: conflictos, cambios y persistencias. En M. Burkart \& M. Giletta (Eds.), Dossier Argentina: zo años de democracia. Instituto de Estudios de América Latina y el Caribe.

Lida, M. (2009). Los orígenes del catolicismo de masas en la Argentina, 1900-1934. Jahrbuchfür Geschichte Lateinamerikas, 46(1), 345-370. https://doi.org/10.7767/ jbla.2009.46.1.345

Lida, M. (2013). La «nación católica» y la historia argentina contemporánea. Corpus. Archivos Virtuales de la Alteridad Americana, 3(2), 1-6. https://doi.org/10.4000/corpusarchivos.579

Lida, M. \& Mauro, D. (Coords.) (2009). Catolicismo y sociedad de masas en Argentina (1900-1950). Prohistoria.

Mallimaci, F. (1991). Movimientos laicales y sociedad en el periodo de entreguerras. La experiencia de la acción católica en Argentina. Cristianismo y Sociedad, (108), 35-71. 
Mallimaci, F. (1992). El catolicismo argentino desde el liberalismo integral a la hegemonía militar. 500 años de cristianismo en Argentina. Cehila.

Mallimaci, F. (1996). Catolicismo y militarismo en Argentina (1930-1983): de la Argentina liberal a la Argentina católica. Revista de Ciencias Sociales, (4), 181-218.

Mallimaci, F. (2000). Catolicismo y liberalismo: las etapas del enfrentamiento por la definición de la modernidad religiosa en América Latina. Sociedad y Religión, (20/21), 25-54.

Mallimaci, F. (2015). El mito de la Argentina laica: catolicismo, política y Estado. Capital Intelectual.

Mallimaci, F., \& Giménez-Béliveau, V. (2006). Historias de vida y método biográfico. En I. Vasilachis de Gialdino (ed.), Estrategias de Investigación Cualitativa (175-212). Gedisa.

Manzano, V. (2010). Juventud y modernización sociocultural en la Argentina de los sesenta. Desarrollo Económico, 1(1), 363-390.

Manzano, V. (2018). La era de la juventud en Argentina. Cultura, política y sexualidad desde Perón hasta Videla. Fondo de Cultura Económica.

Mardomingo, M. T., \& Díaz, J. M. (2003). El escultismo en Castilla y León (1970-1983): un movimiento de juventud para la socialización y la educación en el tiempo libre. Historia de la Educación, (22/23), 139-166.

Margulis, M., \& Urresti, M. (1998). La construcción social de la condición de juventud. En C. Valderrama, H. Cubides, \& M. Laverde (Eds.), Viviendo a toda: jóvenes, territorios culturales y nuevas sensibilidades (pp. 3-21). Siglo del Hombre.

Martín-Criado, E. (1998). Producir la juventud: crítica de la sociología de la juventud. Istmo.

Mosqueira, M. (2014). Santa rebeldía: construcciones de juventud en comunidades pentecostales del Área Metropolitana de Buenos Aires [Tesis doctoral no publicada]. Universidad Buenos Aires.

Papa Francisco (2017). Los Jóvenes, la fe y el discernimiento vocacional. Estado del Vaticano. Pérez-Islas, J. A. (2000). Visiones y versiones: jóvenes, instituciones y políticas de juventud. En L. E. Carvajal (Ed.), Umbrales: cambios culturales, desafíos nacionales y juventud (pp. 195-232). Corporación Región.

Raigada, J. L. P. (2002). Epistemología, metodología y técnicas del análisis de contenido. Estudios de Sociolingüistica, 3(1), 1-42.

Reguillo, R. (2000). Emergencia de culturas juveniles: estrategias del desencanto. Norma. Romero, L. A. (1998). Católicos en movimiento: activismo en una parroquia de Buenos Aires, 1935-1946. Estudios Sociales, 14(1), 89-104. https://doi.org/10.14409/es.v1411.2398

Romero, L. A. (2010). El ejército de Cristo Rey: movilización católica en Buenos Aires, 1934-1945. Cuadernos de Historia, (32), 77-98. 
Serrano-Amaya, J. F. (2002). Ni lo mismo ni lo otro: la singularidad de lo juvenil. Nómadas, (16), 10-25.

Soneira, A. (2008). Trayectorias creyentes/trayectorias sociales. En G. Zalpa, \& H. E. Offerdal (Comps.), ¿El reino de Dios es de este mundo? El papel ambiguo de las religiones en la lucha contra la pobreza. Siglo del Hombre.

Torre, J. C. (2010). Transformaciones de la sociedad argentina. En R. Russell (Ed.), Argentina 1910-2010: balance del siglo. Taurus.

Vasilachis De Gialdino, I. (coord.) (2006). Estrategias de investigación cualitativa. Gedisa.

Zanatta, L. (1996). Del estado liberal a la nación católica: Iglesia y ejército en los orígenes del peronismo, 1930-1943. Universidad Nacional de Quilmes. 